\title{
PROTECTING, BALANCING, AND CONFRONTING: HEALTH-SEEKING AMONG HOMELESS YOUTH IN HO CHI MINH CITY, VIETNAM
}

\author{
Victoria L. Boggiano, Lesley M. Harris, Verena Schmidt, \\ Le Quang Nguyen, Ha An Nguyen, and Michele Barry
}

\begin{abstract}
The objective of this study was to explore health-seeking behaviors and barriers faced in accessing care among homeless youth living in Ho Chi Minh City, Vietnam. Twelve in-depth interviews were conducted with homeless youth aged 18 to 25. Participants were identified using purposive sampling. Data were analyzed using constructivist grounded theory techniques. Interviews with youth revealed that while living on the streets, they had to balance their need for security with attending to their daily survival needs, which led to a disconnection from thinking about their health. When faced with a major health issue, youth turned to their informal networks of support instead of seeking immediate medical care. To manage their basic health needs, youth obtained medicine and health advice from local pharmacies and sought advice from social workers. Homeless youth interviewed in this study relied on an informal network of peers, social workers, and pharmacies when engaging with the health care system. They also faced several barriers to accessing health services, many of which are tied specifically to policies that make homelessness discriminated against in Vietnam. Within Vietnam's unique political and social context, there is a need for increased collaboration between service providers such as health clinics, local pharmacies, and social workers to provide appropriate health services to this vulnerable population.
\end{abstract}

Keywords: Ho Chi Minh City, Vietnam, youth homelessness, health care access, grounded theory, qualitative analysis

Victoria Boggiano (the corresponding author) is a medical student at the Stanford School of Medicine, 871 Warren Way, Palo Alto, CA 94303. Email: vbogg@stanford.edu

Lesley M. Harris PhD is an Assistant Professor of Social Work at the Kent School of Social Work, 109 Patterson Hall, University of Louisville, Louisville, KY 40292. Email: lesley.harris@louisville.edu

Verena Schmidt MSSW is a doctoral candidate at the Kent School of Social Work, 109 Patterson Hall, University of Louisville, Louisville, KY 40292. Email: verena.schmidt@louisville.edu

Le Quang Nguyen is a consultant and former program director with Save the Children in Vietnam's Ho Chi Minh City office, 20 Song Thao, Ward 2, Tan Binh District, Ho Chi Minh City, Vietnam. Email: lequangnguyen1@gmail.com 
International Journal of Child, Youth and Family Studies (2017) 8(3-4): 1-25

Ha An Nguyen is a former project officer with Save the Children in Vietnam's Ho Chi Minh City office, 20 Song Thao, Ward 2, Tan Binh District, Ho Chi Minh City, Vietnam. Email: hantornguyen@gmail.com

Michele Barry MD is the Senior Associate Dean for Global Health, the Director of the Center for Innovation in Global Health, and a Professor of Medicine at the Stanford School of Medicine, 291 Campus Drive, LK3C02, Stanford, CA 94305. Email: michele.barry@stanford.edu 
The United Nations defines "youth" as people between the ages of 15 and 24 (United Nations Educational, Scientific and Cultural Organization, n.d.), and "homelessness" as living on the streets without "a shelter that would fall within the scope of living quarters" (UN Habitat, 2007, p. 119). A report from the Asian Development Bank identifies street youth as

children who might transit to the street, children on the street, [or] children who previously lived on the street with a variety of occupations including beggar, rubbish picker, shoeshine boy or flower seller, sweat shop worker, sex worker or petty criminal (West, 2003, p. 1).

In Vietnam and other emerging economies worldwide, there is a growing population of young people living on the streets who must survive on little income and a fragile social support system (Fern, 2006; Sauvé, 2003).

The phenomenon of youth homelessness is not unique to emerging economies. Studies looking at the lifestyles and behavior patterns of homeless youth have taken place in both developing and industrialized countries, including the United States (Auerswald \& Eyre, 2002; Zerger, Strehlow, \& Gundlapalli, 2008), Canada (Hwang, 2001; Werb, Kerr, Zhang, Montaner, \& Wood, 2010; Woan, Lin, \& Auerswald, 2013), Korea (Kim, 2014), Latin America (Raffaelli, 1999; Raffaelli et al., 2001), and Vietnam (Duong et al., 2008; Fern, 2006; Unite, 2006). Across the globe, young people living on the streets are faced with a myriad of challenges when transitioning to street life, including limited opportunities to generate income, drug and alcohol abuse, and harassment by the police (Duong et al., 2008; Unite, 2006). In addition, researchers have found that homeless youth are more likely to engage in sex work, substance use, and other risk-taking behaviors compared to their non-homeless counterparts (Ensign, 1998; Ennett, Bailey, \& Federman, 1999; Heffron, Skipper, \& Lambert, 1997).

Poor physical health is common among those who are homeless (Ensign \& Bell, 2004; Rice, Tulbert, Cederbaum, Barman-Adhikan, \& Milburn, 2012). Homeless individuals are more likely to have tuberculosis, hypertension, asthma, diabetes, and HIV/AIDS (Zlotnick \& Zerger, 2009) and higher rates of medical hospitalizations (Kushel, Vittinghoff, \& Haas, 2001) when compared to the general population. Living on the streets and engaging in high-risk sexual practices puts youth at risk for contracting HIV/AIDS, sexually transmitted diseases (STDs), and other infectious diseases (Duong et al., 2008; Rotheram-Borus et al., 1992; Song, Safaeian, Strathdee, Vlahov, \& Celentano, 2000). In addition, people experiencing homelessness have higher rates of mental illness (Werb et al., 2010; Woan et al., 2013). However, little is known about how homeless youth conceptualize their health needs and strategize to seek out health care. Moreover, past research with homeless youth in the United States, Canada, and Latin America indicates that adolescents living on the streets rarely seek out formal health services unless they are in need of emergency care (Deisher \& Rogers, 1991; Raffaelli et al., 2001). 
In developing countries, health care for young people living on the streets has focused largely on HIV/AIDS prevention, treatment, and care (Radford, King, \& Warren, 1989). Healthseeking beyond HIV/AIDS services has not been as thoroughly investigated; in fact, scholars who study international homeless adolescent populations call for increasing research to explore the factors that influence homeless youth's health-seeking behavior (Hudson et al., 2010; Raffaelli, 1999; Slesnick, Dashora, Letcher, Erdem, \& Serovich, 2009). This lack of information about the health-seeking behavior of homeless youth extends to Vietnam, where there is a growing population of young people living on the streets (Ensign, 1998; Ensign \& Gittelsohn, 1998; Hong \& Ohno, 2005). The paucity of research on Vietnamese homeless youth is due largely to the hidden nature of this population and the challenges presented by the government's refusal to acknowledge their presence (Edmonds \& Turk, 2002; Gallina \& Masina, 2002; Terre des Hommes Foundation, 2004).

Vietnamese homeless youth are described among local citizens as "bụi đời", or "children of the dust" (Ensign, 1998; Human Rights Watch, 2006). They are colloquially known by social workers and health professionals in Vietnam as "street youth" or "homeless youth". In 2010, the Vietnamese Ministry of Labour, Invalids and Social Affairs (MOLISA) found that more than 160,000 Vietnamese youths were considered orphans or abandoned children; 14,574 children were living in institutions; and 13,000 children resided on the streets (MOLISA 2010, p. 211). For comparison, approximately 30,000 young people live on the streets in Thailand (Khaopa, 2010), and approximately 3,000 homeless adolescents live in Cambodia's major cities (Maza, 2017). How to address the rising population of homeless young people in Vietnam has become a focus of increasing concern for the international community (Ekman, Liem, Duc, \& Axelson, 2008; Fern, 2006; Terre des Hommes Foundation, 2004).

Without support, Vietnamese homeless youth face significant obstacles that impede their ability to live healthy lives. The strict government policies regarding homelessness force homeless youth to hide in parks and markets due to fear of being arrested by the police (Gallina \& Masina, 2002). The homeless population in Vietnam is highly policed, and homeless youth in Vietnam are routinely rounded up by police and sent to detention centers where they are detained for months to years at a time. These facilities, which are often referred to as rehabilitation centers, also house individuals with substance use disorders, sex workers, orphans, and disabled people without family support who have been arrested and detained by law enforcement (Gallina \& Masina, 2002; Human Rights Watch, 2006). Detainees are often subject to extensive hours of forced labor, along with physical and sexual abuse (Amon, Pearshouse, Cohen, \& Schleifer, 2013). There is international agreement that the rehabilitation centers do not create positive change in captives' lives (U.S. Department of State, 2011). Homeless youth in particular remain quite vulnerable once released (Human Rights Watch, 2006), as they are placed once again on the streets without any social support services to assist with their reentry into the community.

Because their health-seeking behavior is so poorly understood (Jones, Presler-Marshall, \& Thuy, 2014; Minh, 2008), it is difficult for non-profit organizations and hospitals to create health 
care services that are well-utilized by Vietnamese homeless youth. In this manuscript, we seek to provide a deeper understanding of the health-seeking behaviors of homeless youth living in Ho Chi Minh City (HCMC), one of Vietnam's major cities, and of the barriers they face in accessing care. Ecological theories of health behavior (McLeroy, Bibeau, Steckler, \& Glanz, 1988), which include individual, interpersonal, and environmental factors (Sallis, Owen, \& Fisher, 2008), helped to frame our study design. Research has shown that changing individual behaviors can decrease the occurrence of chronic diseases (Martin, Haskard-Zolnierek, \& DiMatteo, 2010). However, behavior change necessitates a deeper understanding of the multiple social and environmental factors that influence health-seeking, particularly among vulnerable populations such as homeless

youth in Vietnam. Gaining a deeper understanding of the processes and mechanisms that youth undergo to access care may lead to the development of health care interventions to assist them.

\section{Methods}

\section{Qualitative Approach}

Our research team employed a constructivist grounded theory (CGT) approach (Charmaz, 2014) to examine health-seeking among homeless Vietnamese youth. We used CGT in order to develop a theoretical explanation (Corbin \& Strauss, 2007) - a context-specific framework (Denzin \& Lincoln, 2000; Marshall \& Rossman, 1995; Merriam, 2009) — grounded in data from participants who had themselves experienced homelessness (Corbin \& Strauss, 2007). The CGT approach was compatible with our study because it is based on the assumption that as researchers we are actively co-constructing meaning with our participants through a subjective interrelationship. We allowed discussion topics around health-seeking behavior to emerge as our interviews progressed; following each subset of interviews, new questions and concepts were incorporated into our interview guide (described in more detail below). With this method, our interviews explored the individual, interpersonal, and environmental factors that impacted the health-seeking behavior of the Vietnamese homeless youth we interviewed.

\section{Participants}

For the purposes of this study, we defined youth as individuals between the ages of 18 and 25, and we included youth who had been living on the streets of HCMC for between 1 month and 10 years. We chose the age range of 18 to 25 because of Stanford University Institutional Review Board requirements. We could only include children under 18 if we were able to obtain parental approval, and most of our participants did not have access to a parent or guardian. HCMC was chosen as the location because it is the largest city in Vietnam, one of the fastest-growing cities in Southeast Asia and the destination of choice for most runaway children and youth (Dapice, Gomez-Ibanez, \& Nguyen, 2010). The 19 city districts, which vary in size, contain more than two dozen parks and markets where homeless youth live and work. 
International Journal of Child, Youth and Family Studies (2017) 8(3-4): 1-25

\section{Procedure}

Participants were recruited with the help of staff and social workers affiliated with the Save the Children in Vietnam HCMC office. This method of purposive sampling was appropriate given the hidden nature of the target population (Creswell, 2013). All study participants were contacted initially by one of the social workers who described the project's purpose. Upon arrival, participants were briefed again and given an opportunity to refuse participation when the study was introduced, and again prior to signing the consent form at the start of the interview or focus group. Youth were told that their participation was voluntary and confidential. They were compensated for their time by receiving a gift bag that included an oral health kit (including toothpaste, toothbrush, and floss), a coupon for a health checkup at a clinic, a resource booklet telling them where they could seek social and health services, and 50,000 Vietnamese dong (the equivalent of 2.5 USD). Data collection consisted of two focus groups and 12 one-on-one interviews conducted over 8 weeks.

\section{Focus Groups}

First, two focus groups, with seven participants each, were conducted with formerly and currently homeless youths (Basch, 1987). The focus groups lasted between 60 and 90 minutes. Focus group questions were informed by the study approach described by Rew (2000) and Bender, Thompson, McManus, Lantry, and Flynn (2007) that gave examples of how to pose questions about specific survival strategies to groups of homeless youth. We used these authors' interview approach as a starting place, but asked participating youths to expand and elaborate on the topics that would be most important in relation to health-seeking practices in Vietnam specifically. Participants in the first focus group consisted of seven current or formerly homeless youth leaders identified by a social worker at Save the Children in Vietnam. Formerly homeless youths met the same inclusion criteria as the currently homeless youths (namely, between the ages of 18 and 25 and having spent between 1 month and 10 years living on the streets). The second focus group consisted of seven currently homeless youths who met the study's inclusion criteria and were also identified by the same social worker at Save the Children in Vietnam.

\section{Interviews}

Focus group transcripts were reviewed by authors Boggiano and H. A. Nguyen, who met to discuss themes brought up by participants. Boggiano and Nguyen reviewed participants' responses systematically question by question, after which a semistructured interview guide was created. Following Rew's (2000) example of conducting individual interviews with youth after completion of focus groups, twelve additional homeless youths were recruited to participate in one-on-one interviews (see Appendix for interview questions). Interviews were conducted at the Save the Children in Vietnam HCMC office. Interviews lasted 2 hours on average. Every three interviews, the principal investigator (Boggiano) and an interpreter (H. A. Nguyen) met to discuss the previous three interviews and determine whether there were topics being mentioned by participants that warranted additional mention in the interview guide. Questions were adjusted as 
necessary during each of these check-ins. Together, the investigator and the interpreter, who served as co-researchers, engaged in a collaborative interview process whereby they were co-constructors of knowledge with their research participants (Charmaz, 2014; Harris, Boggiano, Nguyen, \& Pham, 2013).

\section{Analysis}

Eight female and four male homeless youths participated in the one-on-one interviews. The average age of the participants was 23 years, and the average length of time they had lived on the streets was 6 years. Five of the participants had grown up in HCMC, and most of the remaining seven were from provinces located in southern Vietnam's Mekong Delta region. The participants reported that their education ranged from no schooling to college education. Table 1 lists the demographic information for the 12 youths who participated in one-on-one interviews.

Table 1 Demographic Information

\begin{tabular}{|c|c|c|c|c|c|}
\hline Gender & Age & Hometown & $\begin{array}{l}\text { Years on } \\
\text { the streets }\end{array}$ & Current employment & $\begin{array}{l}\text { School grade } \\
\text { completed }\end{array}$ \\
\hline Female & 23 & Ho Chi Minh City & 2 & Sex worker & College \\
\hline Female & 18 & An Giang Province & 2 & Sex worker & Not available \\
\hline Male & 23 & Da Nang City & 8 & Sex worker & Not available \\
\hline Female & 22 & Ho Chi Minh City & 9 & $\begin{array}{l}\text { Selling lottery tickets and } \\
\text { recycling bottles }\end{array}$ & Not available \\
\hline Male & 23 & Vung Tao City & 9.5 & $\begin{array}{l}\text { Working in a restaurant and } \\
\text { odd jobs }\end{array}$ & Not available \\
\hline Female & 18 & Long An Province & 1 & Selling chewing gum & 7 \\
\hline Male & 24 & Tay Ninh Province & 4.5 & Stealing and odd jobs & 5 \\
\hline Male & 25 & Ho Chi Minh City & 10 & Begging & No schooling \\
\hline Female & 25 & Ho Chi Minh City & 10 & Selling drinks and begging & 1 \\
\hline Female & 24 & Tra Vinh Province & 5.5 & $\begin{array}{l}\text { Sex worker and selling } \\
\text { drinks }\end{array}$ & 3 \\
\hline Female & 24 & Ho Chi Minh City & 2 & Sex worker & No schooling \\
\hline Female & 23 & Tay Ninh Province & 8 & Sex worker & 3 \\
\hline
\end{tabular}


Upon completion, the interviews were transcribed and translated by a professional interpreter from Save the Children in Vietnam, and all identifying information was removed prior to analysis. Half of the transcripts were coded line by line by two authors (Boggiano \& Harris). Initial codes were clustered together by topic to develop focused codes. The most frequent and significant focused codes were used to construct a codebook that consisted of 13 codes with definitions. Dedoose, a web-based qualitative data analysis platform, was used to facilitate data organization and coding (Sociocultural Research Consultants, LLC, 2014). The codebook was uploaded to Dedoose, and its coding functions were used to code the first six interview transcripts. The finalized codebook was based on iterative discussions of interview transcripts (Hsieh \& Shannon, 2005; Joffe \& Yardley, 2004).

Next, interrater reliability tests were performed using the other person's coded transcripts to ensure that agreement was reached. After obtaining a pooled Cohen's kappa statistic of 71.5\% (Cohen, 1960; De Vries, Elliott, Kanouse, \& Teleki, 2008), authors Boggiano and Harris met to discuss and adjudicate each excerpt where agreement was not obtained. Cohen's kappa statistic is a widely-used measure to evaluate intercoder agreement as compared to the rate of agreement expected by chance. According to Landis and Koch (1977), the Kappa statistic achieved was considered to be "good agreement". After the adjudication process was complete, and 100\% agreement was reached, the remaining six interviews were coded. Next, a thematic analysis was conducted on the coded transcripts, iteratively refining themes until consensus was reached. The authors maintained memos related to analytic decisions, consulted with other team members, and discussed relationships among the codes that emerged from the data (Charmaz, 2014; Strauss \& Corbin, 2015). We undertook these processes to increase the credibility and trustworthiness of our coding process and application. We also met regularly to supervise each other's coding work and code applications, an approach which increased our ability to be reflexive and improved our teamcoding approach (Barry, Britten, Barber, Bradley, \& Stevenson, 1999).

\section{Ethics}

The Stanford University Institutional Review Board approved all study documents and selection procedures. Boggiano, the data collector, was present at all focus groups and interviews.

\section{Findings}

The following section explores the findings from our qualitative interviews with 12 homeless youths living on the streets of HCMC. Participants described a balancing act of maintaining their physical health in a polluted city with limited opportunities for shelter and hygiene, while also protecting their safety as they confronted dangers such as human trafficking, exploitation, rape, and violence from police and gangs.

The youths reported that their most vulnerable stage of street life was when they first arrived in HCMC and had a limited number of friends and allies, leaving them at the mercy of "the big brothers and sisters" — members of local street youth gangs — who often stole their 
belongings and left them in the park, injured and alone. Over time, the youths developed allies and gained power, but often sought the help of non-homeless friends in the community, including employers and social workers. The challenges faced in maintaining safety caused the street youths to focus less on their health needs, until it became critical for them to do so, such as in the instance of becoming pregnant, having an STD, or being significantly injured. Under these circumstances, the youths found themselves "confronting" their health needs and seeking the support of their trusted allies. Within this dynamic process of "protecting, balancing, and confronting", four properties emerged from our interviews: (a) facing challenges in meeting basic needs, (b) encountering barriers in maintaining health, (c) seeking advice through informal networks, and (d) engaging in health activities. Table 2 lists these properties and their unique dimensions, and each property is described in more detail below.

Table 2 Properties and Dimensions of "Protecting, Balancing, and Confronting"

\begin{tabular}{ll}
\hline Property & Dimensions \\
\hline Facing challenges in meeting basic needs & Acquiring food to eat \\
& Finding safe and comfortable places to sleep \\
Earning an income & Finding a good job \\
Encountering barriers in maintaining health & Maintaining personal hygiene \\
& Living in a stressful environment \\
& Gang violence \\
Seeking advice through informal networks & Police brutality \\
& Peer networks \\
& Social workers \\
Engaging in health activities & Internet and public media \\
& Pharmacies as primary care centers \\
& Reproductive health centers \\
& Hospitals for emergencies \\
\hline
\end{tabular}

\section{Facing Challenges in Meeting Basic Needs}

All 12 participants stated that they faced challenges in obtaining adequate food and shelter. The majority of the participants' time throughout the day was dedicated to earning enough money to eat, finding shelter, and protecting themselves from police, gangs, and other threats.

Youths acknowledged that food insecurity was a barrier to maintaining health. Several reported "not having fixed meals" and often eating only once per day. The preference of all youths who were interviewed was to eat "fast food", which was defined as "unhealthy snacks" or "small cheap meals" from street food stands. However, youths acknowledged that this food was erosive to their overall health in comparison to home-cooked meals. According to one female participant, "Sometimes I just have instant noodles and water all day long: noodles for breakfast, then drink some water, then noodles for lunch, and so on. And I have too much oily food, I feel so sick." 
To prevent food insecurity, youths traveled to parts of the city where they were likely to find free or very low-cost meals. Youths relied heavily on pagodas, local Buddhist places of worship, for "charity meals". These vegetarian meals were prepared by the monks and the nuns living at the pagoda and were free to the entire community. One male participant shared, "If I don't have money, and I see them giving food for free, I will come and ask for one."

When no food was available, participants followed irregular eating schedules. One male youth reported, "If I have money, then I would eat; otherwise, I starve myself." Youths used a variety of coping strategies to stave off the sensation of hunger, such as filling their bellies with water. One female youth described the hierarchy of all three tactics of finding food (eating fast food, going to pagodas for food, and starving): "Some days when the charity food is not available, we starve ourselves drinking water until we have enough money for a cheap meal."

For 10 of the 12 participants in this study, finding a place to sleep at night became a pattern of drifting in and out of finding shelter and living full-time on the streets. When youths were able to secure shelter (as some did for up to a year), they relied on their relatives, friends, or sexual partners to provide them with housing. Participants rented a room when they had enough money to be able to afford a respite from the hectic nature of street life. One female participant stated, "Only when I have money [do I rent a room], otherwise, I don't rent." Another male participant stated that he usually had enough money to rent a room roughly once a month. Moreover, one major preventive factor to sleeping on the streets was being in a stable partnership where shared income and security could help a youth afford or acquire more stable sleeping arrangements. Two female participants in this study were living with boyfriends that they had met on the streets.

When participants could not find housing or shelter, they often fell asleep at the park or in the aisles of hospitals, where they hoped to blend in with patients' family members. However, these tactics came at a high cost due to the danger of being caught by governmental authorities or police, which could result in an arrest or assault. Youths who frequented public places to sleep reported occasionally saving up enough money to rent a hotel room. Overall, searching for safe places to sleep, like finding low-cost or free food to eat, was challenging for the participants in our study, causing them stress and preventing them from focusing on their health and overall livelihood.

\section{Encountering Barriers to Maintaining Health}

Participants highlighted several barriers to accessing health care that they faced while living on the streets: maintaining personal hygiene, earning an income, and the challenge of living in a stressful environment where they were constantly on guard for fear of gangs and police officers.

Several participants relied primarily on public restrooms for maintenance of personal hygiene. When asked where she was doing her personal hygiene, one female participant responded: 
There is a rent bathroom in a house near a park, and I go there to take a shower and do my personal hygiene. They charge 10,000 VND [0.5 USD] for each time you shower, and they do laundry there too for 10,000 VND.

Earning money often placed the youths' health at risk. Seven of the participants stated that some or all of their income was from sex work. Participants acknowledged that engaging in sex work increased the chances of contracting an STD or being physically assaulted by a customer; female youths faced the additional risk of becoming pregnant. Concerning his health, one male participant reported: "I am afraid of fatal diseases like HIV." A female stated: "Customers don't listen to me and push their demands; I feel unsafe when they don't use condoms." Regarding her health-seeking behaviors, one female participant insisted that her clients always wore condoms: "I won't trade my life for money. HIV kills." When youth acquired condoms, the primary sources were hotels (where condoms were sometimes provided free of charge) and nongovernmental organizations. Some youth said they also bought condoms at pharmacies. Another participant stated that she did not use condoms unless customers requested it, because she was allergic to them.

Youths detailed the ways in which having to work and live outside impacted their health. Participants tried to stay healthy by avoiding exposure to extreme weather conditions whenever possible. One male participant spoke of "trying to dodge the rains and the heat" to avoid getting sick. Another youth reported, "Sometimes when the wind changes, I feel chilly to the bone; I will get wet and have a cold ... the rains and heat weaken my resilience."

Youths also lived in the constant presence of violence from gangs, policemen, and customers. When asked about her surroundings, one female participant stated:

I live in Nam Park ${ }^{1}$... It's a park, a place for people to go jogging, to have some fun, but it's also a dangerous place, many types of people living there, sex workers, robbers ... people of all kinds.

Another youth stated that she works in a district well known for sex work. The police, who frequently arrest homeless youths for sleeping in parks or not carrying government identification with them, are another threat that the youths must live with on a daily basis. Of the 12 participants interviewed, eight stated that they had been arrested at least once.

Overall, participants displayed avoidance or disconnect concerning their health. When asked about challenges in maintaining health, one participant stated: "It is my fate, I don't care about that; I haven't visited a hospital at all in my life." Often, youths' avoidance of health care was because of having to attend to other priorities, but also stemmed from a lack of knowledge regarding health services. One female participant stated, "I barely inquire about health services." When asked about how she felt in terms of her health, another youth replied: "I am not as strong

\footnotetext{
1 The name of the park has been changed to protect participant identities.
} 
as before; I will never get back to my previous health condition." Another youth said, "I feel normal, but I don't know what is going on inside my body." Finally, yet another participant said, "I don't know, I just lead a normal life, the sickness will come when it comes, I don't really know how to protect myself, just live day by day." Overall, participants' health-seeking behaviors were disrupted by challenges in maintaining their basic health needs.

\section{Seeking Health Advice Through Informal Networks}

Participants reported seeking advice concerning their health through informal networks, especially peers, social workers, and the internet and public media. When confronted with a major health dilemma (e.g., an STD or pregnancy), the youths turned to their informal networks for advice instead of seeking immediate medical care.

Social workers were also key resources for homeless youth when seeking advice about health. One female participant elaborated: "They counsel us and give us moral support, and they buy medicine for me." According to another female participant, social workers "showed me types of sexually transmitted infections, the symptoms, and how to prevent them ... they advised me when I took a blood test."

Participants reported that they often utilized the internet and public media such as government public health campaigns when seeking health advice. Several participants described how much information they learned from the internet, which they accessed by visiting internet cafes located across HCMC. One male participant noted that he learned how to use condoms because of the "instructions on the packaging", and that in the past he had seen many brochures on how to use them.

\section{Engaging in Health Activities}

All 12 youths who participated in this study mentioned that they frequently went to $n h a$ thuoc [local pharmacies] to buy medicine when they were not feeling well, instead of using primary care doctors. One participant explained, "I go to the pharmacy and buy medicine. I tell [the pharmacist] how I feel, and they know what to give me." For all participants, pharmacies were accessed once illnesses became too severe to bear on their own. If a participant had a cough or a headache or was worried about stomach pains that would not go away, he or she would turn to the pharmacist for help in deciding which medicine to buy.

Among the female participants in our study, becoming pregnant created a need for health care services that mandated a trip to the hospital. Reproductive health thus became one means of entry into the health care system for homeless female youth. One female participant commented, "It is simple, everybody goes there to deliver their baby." Another youth explained, "Yes, when I delivered, I did go to the doctor." Some youths also received testing for STDs at local clinics, which social workers had connected them to. 
Hospitals were used by youths only for emergencies. One participant reported, "Going to the hospital means not earning money ... I have no money for the hospital." For another participant who came down with appendicitis, going to the hospital was the last resort but became a necessity when she was too sick to walk and needed urgent surgery. Seven youths (both male and female) stated that they had gone to the hospital at some point during their time on the streets: one for appendicitis, two to give birth, one because she fainted, one for an STD test, one for severe nausea and vomiting, and one for dengue fever (for which he was hospitalized for a month). Overall, youths indicated that they were preoccupied with their "day-to-day life," as well as securing food and shelter, and tended to medical issues only when they could not wait any longer.

In terms of preventive factors that helped youth maintain their health, participants remarked that engaging with local non-governmental organizations — particularly if the staff at these organizations were trusted by and well-known to the youth - enabled them to obtain services such as testing for STDs. Though not always available to the participants in our study, these factors, when present, helped them to learn more about their bodies and maintain their health to the greatest extent possible.

\section{Discussion}

To date, the health experiences of homeless youth living on the streets of Vietnam's major cities have been poorly studied (Fern, 2006; Terre des Hommes Foundation, 2004). There are many factors that lead Vietnamese children and adolescents to the streets, and many of those factors are present among both Vietnamese street youth and homeless youth from other nations. Many children in Vietnam - including several of our participants - come to the streets to escape abuse at home or to earn money to send back to their families (Fern, 2006; Unite, 2006). Those who identify as lesbian, gay, bisexual, or transgender often seek out street life to escape communities that have terrorized them for their sexual orientation or gender preferences (Save the Children \& Institute of Social and Medical Studies, 2015), which is also true for homeless young people in other regions of the globe (Keuroghlian, Shtasel, \& Bassuk, 2014). Unique to Vietnam, however, is the country's communist government structure that continues to devalue this marginalized population by enforcing policies that cause the youth to be thrown in jail if discovered to be living on the streets. This sustains a culture that tries to make them invisible rather than create muchneeded social services to assist them (Human Rights Watch, 2006). In addition, generations of wealthy families in Vietnam's major cities have created a structuralized racism that places certain Vietnamese ethnic groups and social clans above others (Krajan, 2017), preventing those in the lower classes from escaping the poverty that forces many of the thousands of homeless youths to earn money by picking up trash or selling sex.

The communism and classism that defines much of urban life in Vietnam does not create room for social services such as health care facilities to cater to homeless youth. Moreover, given the hidden nature of the juvenile street population in major cities like HCMC or Hanoi (Fern, 
2006), it is difficult to gain a deeper sense of what their health needs are or how they engage with the health care system. While the negative health impact of living on the streets is well documented (Beharry, 2012; Bao, Whitbeck, \& Hoyt, 2000; Bender et al., 2007; Heffron et al., 1997), participants in our study engaged in formal health-seeking behaviors only when their health became such a pressing issue that it could not be ignored. Youths faced several barriers to maintaining their health: challenges finding places to sleep and food to eat, having few resources to spend on accessing health care, and living in a constant environment of fear from gang violence, police brutality, and assault. This finding is corroborated by other literature on youth homelessness (Karabanow, 2009; Ensign, 1998). As our participants emphasized, many homeless Vietnamese youths avoid engagement with medical facilities for fear of being caught by police or government officials and sent to rehabilitation centers. When youths did take action with regard to their health, it was often through pharmacies that served as primary care centers (Ngo et al., 2007) or via informal networks of peers, members of the community, and social workers.

Applying the ecological model to our findings (McLeroy et al., 1988), participants' individual characteristics gave them enough resiliency to withstand difficult circumstances. They sought out opportunities to find food, shelter, earn an income, and develop networks that they could rely on for help. However, individual and interpersonal factors were not able to overcome the detrimental environmental factors that youths faced, such as threats to their physical safety. Although some pharmacists served as facilitators by helping youths obtain medicine, barriers such as limited resources with which to buy food or a safe place to sleep made accessing health services an almost insurmountable challenge.

Based on what we learned from homeless youths during this study, we offer recommendations about ways to improve their engagement with health services. To date, while there has been extensive research looking at how pharmacies throughout Vietnam are operated (Van Duong, Binns, \& Van Le, 1997), there has been little research looking at ways to successfully involve pharmacies in public health endeavors. Taking the findings of previous studies a step further (Ngo et al., 2007), pharmacies can play a crucial role in helping homeless youth improve their health and can act as a liaison to other health care services. Throughout Vietnam, locally run pharmacies can be found on each street corner. All 12 participants in our interviews talked about seeking the help of pharmacists whenever they began to feel sick.

Studies have shown that mobile health care vans that can be parked near homeless youth have been effective in increasing access to health services for this population. A study investigating illness experiences among homeless youth in Seattle (Ensign \& Bell, 2004) found that mobile vans provided greater access to youth than did hospitals or medical centers. In such care settings, young people can obtain STD testing, vaccinations, and other routine primary care (Ensign \& Bell, 2004). However, as mentioned previously, being homeless is heavily policed in Vietnam, and living on the streets greatly increases one's risk of being arrested if one is discovered in public parks or sleeping on the street without a government-issued identification card. This aspect of Vietnamese society might limit the effectiveness of publicly placing mobile vans in "hot spots" where homeless 
youth reside in HCMC. Our results indicate that participants most commonly accessed health care resources from the internet or directly through pharmacy care (i.e., self-diagnosing, and ordering medicine from pharmacies without seeing a doctor). However, there might be potential for mobile health care centers if there could be collaboration and agreement with the Vietnamese government on the acceptability and feasibility of this intervention.

Another model of care is the "drop-in center". In the United States, these centers provide services such as meals, clothing, showers, access to transportation, and occasionally casemanagement services. In his exploration of how homeless youth are able to successfully exit street life, Karabanow (2009) stressed the importance of health care centers such as drop-in clinics that youths can access. Health clinics, he noted, are one avenue where homeless young people meet "supportive and healthy contacts" that help them not only meet their basic health needs but also begin to develop the skills necessary to exit street life (Karabanow, 2009, p. 20). Studies have shown that drop-in centers can serve as social support centers and connectors for street youth, and provide a gateway to treatment for substance abuse and mental health problems (Tsemberis, Moran, Shinn, Assmussen, \& Shern, 2003).

Above all, however, the findings from this study underscore the need for ending the practice of systematic roundups of Vietnamese street youth, due to the negative impact on their ability to seek out health care. If the Vietnamese government continues to treat homeless youth as illegal and repeatedly send them to rehabilitation centers, their health will continue to deteriorate.

\section{Limitations}

There are a few limitations to our study. Our small sample size and purposive sampling strategy meant that we were speaking with one small subset of the homeless youth in HCMC. We therefore cannot conclude that our findings are representative of the health-seeking behavior patterns of all homeless youth in Vietnam. In addition, the limited time collecting data in Vietnam hindered efforts at uncovering all facets of the complexity of homelessness in Vietnam. This article is a first step towards uncovering elements of health-seeking behavior among homeless youth in HCMC and Vietnam more generally. Despite these noted limitations, our study was able to gain a deeper understanding of Vietnamese homeless youth, their health needs and strategies, and the barriers they face in accessing health care.

\section{Conclusion}

While the damaging health consequences of homelessness in Vietnam have been studied previously (Duong et al., 2008), the health-seeking behaviors of young people living on the streets and their barriers to accessing health care services have remained poorly understood. This study seeks to contribute a greater understanding of health and health-seeking behavior among homeless youth in HCMC through our description of "protecting, balancing, and confronting". For young people living on the streets, health maintenance is a low priority given the difficulties faced in meeting even basic needs like food and shelter. Several barriers exist that impede young people's 
access to the health care system, largely stemming from policies that make homelessness discriminated against in Vietnam, as street children are frequently jailed by police during street sweeps (Human Rights Watch, 2006). In order to help youth begin to prioritize their physical and mental health, a collaborative approach among the government, law enforcement, health clinics, nongovernmental organizations, peer networks, and local pharmacies is required. 
International Journal of Child, Youth and Family Studies (2017) 8(3-4): 1-25

\section{References}

Amon, J. J., Pearhouse, R., Cohen, J., \& Schleifer, R. (2013). Compulsory drug detention centers in China, Cambodia, Vietnam, and Laos: Health and human rights abuses. Health and Human Rights, 15(2), 124-137.

Auerswald, C. L., \& Eyre, . (2002). Youth homelessness in San Francisco: A life cycle approach. Social Science \& Medicine, 54(10), 1497-1512. doi:10.1016/S0277-9536(01)00128-9

Bao, W. N., Whitbeck, , \& Hoyt, . (2000). Abuse, support, and depression among homeless and runaway adolescents. Journal of Health and Social Behavior, 41(4), 408-420. doi:10.2307/2676294

Barry, C. A., Britten, N., Barber, N., Bradley, C., \& Stevenson, F. (1999). Using reflexivity to optimize teamwork in qualitative research. Qualitative Health Research, 9(1), 26-44. doi:10.1177/104973299129121677

Basch, C. E. (1987). Focus group interview: An underutilized research technique for improving theory and practice in health education. Health Education \& Behavior, 14(4), 411-448. doi:10.1177/109019818701400404

Beharry, M. S. (2012). Health issues in the homeless youth population. Pediatric Annals, 41(4), 154-156. doi:10.3928/00904481-20120307-12

Bender, K., Thompson, , McManus, H., Lantry, J., \& Flynn, P. M. (2007). Capacity for survival: Exploring strengths of homeless street youth. Child Youth Care Forum, 36(1), 25-42. doi:10.1007/s10566-006-9029-4

Charmaz, K. (2014). Constructing grounded theory (2nd ed.). London, UK: Sage.

Cohen, J. (1960). A coefficient of agreement for nominal scales. Educational and Psychological Measurement, 20(1), 37-46. doi:10.1177/001316446002000104

Corbin, J., \& Strauss, A. (2007). Basics of qualitative research: Techniques and procedures for developing grounded theory (3rd ed.). Thousand Oaks, CA: Sage.

Creswell, J. W. (2013). Qualitative inquiry and research design: Choosing among five approaches (3rd ed.). Thousand Oaks, CA: Sage.

Dapice, D., Gomez-Ibanez, ,\& Nguyen, . (2010). Ho Chi Minh City: The challenges of growth (UNDP-Harvard Policy Dialogue Paper Number 2). Ho Chi Minh City, Vietnam: United Nations Development Programme in Vietnam. Retrieved from http://www.undp.org/content/dam/vietnam/docs/Publications/24699_20911_HCM_Challen ges_of_growth.pdf 
International Journal of Child, Youth and Family Studies (2017) 8(3-4): 1-25

Deisher, R. W., \& Rogers, . (1991). The medical care of street youth. Journal of Adolescent Health, 12(7), 500-503. doi:10.1016/0197-0070(91)90077-Y

Denzin, N. K., \& Lincoln, Y. S. (2000). Handbook of Qualitative Research (2nd ed.). Thousand Oaks, CA: Sage.

De Vries, H., Elliott, , Kanouse, D. E., \& Teleki, . (2008). Using pooled kappa to summarize interrater agreement across many items. Field Methods, 20(3), 272-282. doi: $10.1177 / 1525822$ X08317166

Duong, C. T., Nguyen, , Hoang, , Nguyen, , Do, , Pham, V. H., \& Detels, R. (2008). Sexual risk and bridging behaviors among young people in Hai Phong, Vietnam. AIDS and Behavior, 12(4), 643-651. doi:10.1007/s 10461-007-9265-0

Edmonds, E. V., \& Turk, C. (2002). Child labor in transition in Vietnam (Policy research paper 2774). World Bank, Development Economics Research Support Group, Washington, DC. Retrieved from http://elibrary.worldbank.org/doi/abs/10.1596/1813-9450-2774

Ekman, B., Liem, , Duc, H. A., \& Axelson, H. (2008). Health insurance reforms in Vietnam: A review of recent developments and future challenges. Health Policy and Planning, 23(4), 252-263. doi:10.1093/heapol/czn009

Ennett, S. T., Bailey, , \& Federman, . (1999). Social network characteristics associated with risky behaviors among runaway and homeless youth. Journal of Health and Social Behavior, 40(1), 63-78. doi:10.2307/2676379

Ensign, J. (1998). Health issues of homeless youth. Journal of Social Distress and the Homeless, 7(3), 159-174. doi:10.1023/A:1022931628497

Ensign, J., \& Bell, M. (2004). Illness experiences of homeless youth. Qualitative Health Research, 14(9), 1239-1254. doi:10.1177/1049732304268795

Ensign, J., \& Gittelsohn, J. (1998). Health and access to care: Perspectives of homeless youth in Baltimore City, USA. Social Science \& Medicine, 47(12), 2087-2099. doi:10.1016/S02779536(98)00273-1

Fern, P. (2006). Migrant working children in Ho Chi Minh City: Emerging trends between economic migrants and runaway child workers (Seminar paper). Georgetown University, Washington, DC. Retrieved from http://digitalcollections.sit.edu/cgi/viewcontent.cgi? article=1317\&context=isp_collection 
International Journal of Child, Youth and Family Studies (2017) 8(3-4): 1-25

Gallina, A., \& Masina, P. (2002). Street children in Vietnam: An inquiry into the roots of poverty and survival livelihood strategies (Research report no. 3/2002). Federico Caffè Centre, Roskilde University, Roskilde, Denmark. Retrieved from http://www.streetchildrenresources.org/resources/street-children-in-vietnam-an-inquiryinto-the-roots-of-poverty-and-survival-livelihood-strategies/

Harris, L. M., Boggiano, V., Nguyen, ,\& Pham, . (2013). Working in partnership with interpreters: Studies on individuals affected by HIV/AIDS in Vietnam. Qualitative Health Research, 23(10), 1408-1418. doi:10.1177/1049732313506964

Heffron, W. A., Skipper, , \& Lambert, L. (1997). Health and lifestyle issues as risk factors for homelessness. The Journal of the American Board of Family Practice, 10(1), 6-12.

Hong, D. K., \& Ohno, K. (2005). Street Children in Vietnam. Tokyo, Japan: National Graduate Institute for Policy Studies. Retrieved from http://www.grips.ac.jp/vietnam/KOarchives/doc/EP17_DP6.pdf

Hsieh, H.-F., \& Shannon, . (2005). Three approaches to qualitative content analysis. Qualitative Health Research, 5(9), 1277-1288. doi:10.1177/1049732305276687

Hudson, A. L., Nyamathi, A., Greengold, B., Slagle, A., Koniak-Griffin, D., Khalilifard, F., \& Getzoff, D. (2010). Health-seeking challenges among homeless youth. Nursing Research, 59(3), 212-218. doi:10.1097/NNR.0b013e3181d1a8a9

Human Rights Watch. (2006). "Children of the dust": Abuse of Hanoi street children in detention (Report). Retrieved from https://www.hrw.org/report/2006/11/12/childrendust/abuse-hanoi-street-children-detention

Hwang, S. W. (2001). Homelessness and health. Canadian Medical Association Journal, 164(2), 229-233. Retrieved from http://pubmedcentralcanada.ca/pmcc/articles/PMC80688/pdf/20010123s00027p229.pdf

Joffe, H., \& Yardley, L. (2004). Content and thematic analysis. In D. F. Marks \& L. Yardley (Eds.), Research methods for clinical and health psychology (1st ed., pp 56-69). London, UK: Sage.

Jones, N., Presler-Marshall, E., \& Thuy, D. B. (2014). Falling between the cracks: How poverty and migration are resulting in inadequate care for children living in Viet Nam 's Mekong Delta (Report). London, UK: Overseas Development Institute. Retrieved from http://resourcecentre.savethechildren.net/sites/default/files/documents/9306.pdf. 
International Journal of Child, Youth and Family Studies (2017) 8(3-4): 1-25

Karabanow, J. (2009). How young people get off the street: Exploring paths and processes. In J. D. Hulchanski, P. Campsie, S. Chau, S. Hwang, \& E. Paradis (Eds.), Finding home: Policy options for addressing homelessness in Canada (e-book, pp. 1-22). Toronto, ON: Cities Centre Press, University of Toronto.

Keuroghlian, A. S., Shtasel, D., \& Bassuk, E. L. (2014). Out on the street: A public health and policy agenda for lesbian, gay, bisexual, and transgender youth who are homeless. American Journal of Orthopsychiatry, 84(1), 66-72. doi:10.1037/h0098852

Khaopa, W. (2010). The unsung supporters of street children (Online news forum). Thai Visa: The Nation. Retrieved from https://www.thaivisa.com/forum/topic/376763-the-unsungsupporters-of-thailands-street-children/

Kim, S. K. (2014). A review of research on runaway and homeless youth: A comparison of trends between American and South Korean journals from 2001 to 2010. Child and Adolescent Social Work Journal, 31(2), 107-118. doi:10.1007/s10560-013-0313-5

Krajan, E. A. (2017). Enduring poverty: Explanations for the persistence of minority poverty in Vietnam (Doctoral dissertation). Naval Postgraduate School, Monterey, CA. Retrieved from https://calhoun.nps.edu/bitstream/handle/10945/53004/17Mar_Krajan_Emilie.pdf?sequence $=1$

Kushel, M. B., Vittinghoff, E., \& Haas, J. S. (2001). Factors associated with the health care utilization of homeless persons. Journal of the American Medical Association, 285(2), 200 206. doi:10.1001/jama.285.2.200

Landis, J. R., \& Koch, . (1977). The measurement of observer agreement for categorical data. Biometrics, 33(1), 159-174. doi:10.2307/2529310

Marshall, C., \& Rossman, G. B. (1995). Designing qualitative research (2nd ed.). Thousand Oaks, CA: Sage.

Martin, L. R., Haskard-Zolnierek, K. B., \& DiMatteo, M. R. (2010). Health behavior change and treatment adherence: Evidence-based guidelines for improving healthcare. New York, NY: Oxford University Press.

Maza, C. (2017). Survey counts homeless youth. The Phnom Penh Post. Retrieved from http://www.phnompenhpost.com/national/survey-counts-homeless-youth

McLeroy, K. R., Bibeau, D., Steckler, A., \& Glanz, K. (1988). An ecological perspective on health promotion programs. Health Education Quarterly, 15(4), 351-377. doi:10.1177/109019818801500401

Merriam, S. B. (2009). Qualitative Research: A guide to design and implementation. San Francisco, CA: Jossey-Bass. 
International Journal of Child, Youth and Family Studies (2017) 8(3-4): 1-25

Minh, T. L. T. (2008). Sexuality and sexual and reproductive health consequences among homeless adolescents in Ho Chi Minh City, Vietnam (Doctoral dissertation). Mahidol University, Salaya, Thailand. Retrieved from http://mulinet11.li.mahidol.ac.th/thesis/2551/cd415/4938062.pdf

Ministry of Labour, Invalids, and Social Affairs. (2010). An analysis of the situation of children in Viet Nam. Retrieved from http://www.unicef.org/sitan/files/SitAnViet_Nam_2010_Eng.pdf

Ngo, A. D., Ratliff, ,McCurdy, , Ross, M. W., Markham, C., \&. Pham, . (2007). Health-seeking behaviour for sexually transmitted infections and HIV testing among female sex workers in Vietnam. AIDS Care 19(7), 878-887. doi:10.1080/09540120601163078

Radford, J. L., King, A. J., \& Warren, W. K. (1989). Street youth and AIDS. Kingston, ON: Health and Welfare Canada.

Raffaelli, M. (1999). Homeless and working street youth in Latin America: A developmental review. Interamerican Journal of Psychology, 33(2), 7-28.

Raffaelli, M., Koller, S. H., Reppold, C. T., Kuschick, M. B., Krum, F. M., \& Bandeira, D. R. (2001). How do Brazilian street youth experience the street? Analysis of a sentence completion task. Childhood, 8(3), 396-415. doi:10.1177/0907568201008003006

Rew, L. (2000). Friends and pets as companions: Strategies for coping with loneliness among homeless youth. Journal of Child and Adolescent Psychiatric Nursing, 13(3), 125-132. doi:10.1111/j.1744-6171.2000.tb00089.x

Rice, E., Tulbert, E., Cederbaum, J., Barman-Adhikari, A., \& Milburn, N. G. (2012). Mobilizing homeless youth for HIV prevention: A social network analysis of the acceptability of a faceto-face and online social networking intervention. Health Education Research, 27(2), 226236. doi:10.1093/her/cyr113

Rotheram-Borus, M. J., Meyer-Bahlburg, L.,Koopman, C., Rosario, M., Exner, , Henderson, R., ... Gruen, . (1992). Lifetime sexual behaviors among runaway males and females. The Journal of Sex Research, 29(1), 15-29. doi:10.1080/00224499209551631

Sallis, J. F., Owen, N., \& Fisher, . (2008). Ecological models of health behavior. In K. Glanz, B. K. Rimer, \& K. Viswanath (Eds.), Health behavior and health education (4th ed., pp. 465486). San Francisco, CA: John Wiley \& Sons. Retrieved from http://riskybusiness.web.unc.edu/files/2015/01/Health-Behavior-and-HealthEducation.pdf\#page $=503$

Sauvé, S. (2003). Changing paradigms for working with street youth: The experience of Street Kids International. Children Youth and Environments, 13(1), 314-333. 
International Journal of Child, Youth and Family Studies (2017) 8(3-4): 1-25

Save the Children, \& Institute of Social and Medical Studies. (2015). Being LGBT young people in Vietnam: Life on the streets and the light through the crack. A summary of research findings. Ho Chi Minh City, Vietnam: Author. Retrieved from https://resourcecentre.savethechildren.net/sites/default/files/documents/lgbt_young_people in_vietnam___save_the_childrens_report.pdf

Slesnick, N., Dashora, P., Letcher, A., Erdem, G., \& Serovich, J. (2009). A review of services and interventions for runaway and homeless youth: Moving forward. Children and Youth Services Review, 31(7), 732-742. doi:10.1016/j.childyouth.2009.01.006

Sociocultural Research Consultants, LLC. (2014). Dedoose, version 5.0.11 [Web application]. Los Angeles, CA: Author. Retrieved from http://www.dedoose.com

Song, J. Y., Safaeian, M., Strathdee, S. A., Vlahov, D., \& Celentano, D. D. (2000).The prevalence of homelessness among injection drug users with and without HIV infection. Journal of Urban Health, 77(4), 678-687. doi:10.1007/BF02344031

Strauss, A. \& Corbin, J. (2015). Basics of qualitative research: Techniques and procedures for developing grounded theory (4th ed.). Thousand Oaks, CA: Sage.

Terre des Hommes Foundation. (2004). A study on street children in Ho Chi Minh City. National Political Publisher, Hanoi. Retrieved from http://static1.squarespace.com/static/526c21b5e4b0d43e45f6c4c2/t/57f1d0078419c2912d15 b32c/1475465229895/SC_A,study,on,Street,Children_2011.doc\&usg=AOvVaw19NCtlgPL bz2hGGhzGJawq

Tsemberis, S. J., Moran, L., Shinn, M., Asmussen, S. M., \& Shern, D. L. (2003). Consumer preference programs for individuals who are homeless and have psychiatric disabilities: A drop-in center and a supported housing program. American Journal of Community Psychology, 32(3/4), 305-317. doi:10.1023/B:AJCP.0000004750.66957.bf

UN-Habitat. (2007). Global Report on Human Settlements: Enhancing urban safety and security.. London, UK: Earthscan Publications. Retrieved from http://unhabitat.org/books/global-report-on-human-settlements-2007-enhancing-urbansafety-and-security/

Unite, C. (2006). An chua? (Have you eaten yet?): Assessing nonformal education for street youth in Hanoi, Vietnam (Master's thesis). Saint Mary's University, Halifax, NS. Retrieved from http://library2.smu.ca:8080/handle/01/22111\#.WgYqKIhryUk

United Nations Educational, Scientific and Cultural Organization. (n.d.). What do we mean by “youth"? Retrieved February 20, 2016, from http://www.unesco.org/new/en/social-andhuman-sciences/themes/youth/youth-definition/ 
International Journal of Child, Youth and Family Studies (2017) 8(3-4): 1-25

U.S. Department of State. (2011). Vietnam: 2010 country report on human rights practices. Bureau of Democracy, Human Rights, and Labor. Retrieved from https://www.state.gov/j/drl/rls/hrrpt/2010/eap/154408.htm

Van Duong, D., Binns, ,\& Van Le, T. (1997). Availability of antibiotics as over-the-counter drugs in pharmacies: A threat to public health in Vietnam. Tropical Medicine and International Health, 2(12), 1133-1139. doi:10.1046/j.1365-3156.1997.d01-213.x

Werb, D., Kerr, T., Zhang, R., Montaner, J. S. G., \& Wood, E. (2010). Methamphetamine use and malnutrition among street-involved youth. Harm Reduction Journal, 7(5). doi: $10.1186 / 1477-7517-7-5$

West, A. (2003). At the margins: Street children in Asia and the Pacific (Poverty and Social Development Paper No. 8). Manila, Philippines: Asian Development Bank. Retrieved from http://hdl.handle.net/11540/2287

Woan, J., Lin, J., \& Auerswald, C. (2013). The health status of street children and youth in lowand middle-income countries: A systematic review of the literature. Journal of Adolescent Health, 53(3), 314-321. doi:10.1016/j.jadohealth.2013.03.013

Zerger, S., Strehlow, A. J., \& Gundlapalli, A. V. (2008). Homeless young adults and behavioral health: An overview. American Behavioral Scientist, 51(6), 824-841. doi: $10.1177 / 0002764207311990$

Zlotnick, C., \& Zerger, S. (2009). Survey findings on characteristics and health status of clients treated by the federally funded (US) Health Care for the Homeless Programs. Health and Social Care in the community, 17(1), 18-26. doi:10.1111/j.1365-2524.2008.00793.x 


\section{Appendix}

\section{Interview Questions for One-On-One Interviews}

\section{Demographic questions}

Age:

Hometown:

Length of time living on the streets:

What are the ways that you have made money?

Selling food

Selling drinks

Selling lottery tickets

Sex work

Stealing

Other

What is your sexual orientation?

Who are your clients?

Are they Vietnamese?

Are they foreign?

Both?

What is the gender of your clients?

Male?

Female?

Both?

\section{Individual Factors}

How long have you been living on the streets?

What is street life like for you?

What first brought you to the streets?

When you first moved to the streets, did you feel safe? Why?

Do you feel safe now?

What do you do to protect yourself?

Day by day, how do you feel?

Has this changed at all since you first got to the streets?

When you have a cough, what do you do?

What illnesses are you the most concerned about?

What are the most common illnesses you and other street youth experience?

How do you get information about how to take care of yourself?

What do you do to keep yourself from getting sick?

How did you learn to do this?

How often do you use condoms?

How do you get the condoms?

How do you know about using condoms? 


\section{Interpersonal Factors}

What was your relationship with your family like growing up?

How do you earn a living on the streets?

What is your relationship with other people on the streets?

Have you met anyone who made a big impact on your life on the streets?

When you need advice/counsel, who/where do you go to?

What makes you feel safe? What makes you feel unsafe?

\section{Environmental Factors}

Can you tell me more about where you live and work on the streets?

What is your relationship with the government, the police, and the authorities?

When you first got to the streets, what would you eat and where would you go for food?

Now-a-days, what do you eat and where do you go for food?

How often do you eat?

How often do you feel hungry?

Where do you work during the day? Where do you sleep at night? Why?

Can you tell me about a time where you felt unsafe on the streets?

Do you know of someone who was taken by the police? If yes, then what happened to them?

When is the last time you went to the doctor?

When is the last time you went to the pharmacy?

How do you find out about health services? 